\title{
Role of MRI as first-line modality in the detection of previously undiagnosed otosclerosis: a single tertiary institute experience
}

\author{
Bela Purohit ${ }^{1,2^{*}}$, Katya Op de beeck ${ }^{1}$ and Robert Hermans ${ }^{1}$
}

\begin{abstract}
Background: Otosclerosis causes conductive, sensorineural and mixed hearing loss ( $\mathrm{CHL}, \mathrm{SNHL}, \mathrm{MHL}$ ) and tinnitus in young adults. It is best diagnosed on high-resolution $\mathrm{CT}(\mathrm{HRCT})$. Occasionally, patients presenting with $\mathrm{SNHL}$ and/or tinnitus may undergo temporal bone MRI as the first investigation. In this study, we have described the role of MRI as the first-line modality in the detection of previously undiagnosed otosclerosis.

Using search words 'MRI otosclerosis' we found 15 cases in the PACS of our institute, (University Hospitals, KU Leuven, Belgium) from 2003 to 2018. Of these, 2 were known cases of otosclerosis, hence excluded from the study. The remaining 13 patients underwent MRI as first-line investigation for unilateral SNHL (8/13), bilateral SNHL (3/13), unilateral MHL (1/13) and bilateral pulsatile tinnitus (1/13). All MRI studies were reported by the same senior radiologist.
\end{abstract}

Results: Of these 13 cases, 12 were reported as showing MRI features suspicious for otosclerosis. The typical positive findings in these cases were intermediate $\mathrm{T} 1$ signal and post-contrast enhancement in the perilabyrinthine/ pericochlear regions. Out of 13 patients, 9 underwent subsequent HRCT, confirming otosclerosis in all. The single MRI which was reported as normal initially showed otosclerosis on HRCT. Retrospective evaluation of this MRI study showed subtle positive findings of otosclerosis.

Conclusion: The end point of this study was to validate the subtle findings of otosclerosis on MRI, by comparison to the gold-standard modality HRCT. Our hypothesis is that in the appropriate clinical setting, familiarity with MRI features of otosclerosis would increase the diagnostic 'catch' in the first 'net' itself i.e. first-line MRI.

Keywords: MRI temporal bones, HRCT temporal bones, Otosclerosis, Perilabyrinthine/pericochlear enhancement

\section{Key points}

- Patients presenting with classic clinical manifestations of otosclerosis like CHL/ MHL typically undergo HRCT which is considered the imaging modality of choice.

\footnotetext{
* Correspondence: purohitbela@yahoo.co.in

${ }^{1}$ Department of Radiology, University Hospitals, KU Leuven, Leuven, Belgium ${ }^{2}$ Department of Neuroradiology, National Neuroscience Institute, Singapore, Singapore
}

- Occasionally, patients with clinically undiagnosed otosclerosis presenting with SNHL or tinnitus may undergo primary MRI instead of HRCT.

- MRI findings of otosclerosis are subtle and may be overlooked, especially if MRI is performed as the first-line scan.

- Typical MRI features of otosclerosis include intermediate T1 signal and post-contrast enhancement in the perilabyrinthine and pericochlear regions.

\section{Springer Open}

(c) The Author(s). 2020 Open Access This article is licensed under a Creative Commons Attribution 4.0 International License, which permits use, sharing, adaptation, distribution and reproduction in any medium or format, as long as you give appropriate credit to the original author(s) and the source, provide a link to the Creative Commons licence, and indicate if changes were made. The images or other third party material in this article are included in the article's Creative Commons licence, unless indicated otherwise in a credit line to the material. If material is not included in the article's Creative Commons licence and your intended use is not permitted by statutory regulation or exceeds the permitted use, you will need to obtain permission directly from the copyright holder. To view a copy of this licence, visit http://creativecommons.org/licenses/by/4.0/. 


\section{Background}

Otosclerosis is a unique bony dysplasia of the otic capsule commonly seen in young and middle-aged adults. The disease is bilateral in almost $85 \%$ cases. Otosclerosis is characterised by the replacement of normal ivory-like enchondral bone by spongy vascular bone. This decalcified vascular bone of the otic capsule eventually recalcifies and becomes more solid. These phases of increased vascularity, decalcification and subsequent recalcification cause the typical clinical manifestations of this disease [1-3]. Two major patterns are seen: (1) fenestral type in which otosclerotic foci are restricted to the lateral wall of the otic capsule, especially around the oval window $(\mathrm{OW})$ and round window (RW) and (2) retrofenestral or cochlear type, in which otosclerotic foci predominantly involve the pericochlear regions. Fenestral involvement may eventually progress to cochlear involvement; hence, these manifestations are considered as a continuum of the same disease process rather than separate entities. Fenestral otosclerosis typically causes stapes fixation and CHL. Cochlear otosclerosis may present with SNHL, MHL, vestibular symptoms and/or pulsatile tinnitus (PT) [1-4].

Patients presenting with the classic clinical manifestations of fenestral otosclerosis (CHL, absent stapedial reflexes) usually undergo non-contrast HRCT of the temporal bones which is the modality of choice for the diagnosis and grading of otosclerotic plaques [1-6]. However, occasionally, patients presenting with SNHL

Table 1 Clinical presentation, MRI and HRCT findings of 9 patients who underwent first-line MRI and ultimately confirmed as otosclerosis on subsequent HRCT

\begin{tabular}{|c|c|c|c|c|c|}
\hline $\begin{array}{l}\text { Case number/ } \\
\text { sex/age }\end{array}$ & $\begin{array}{l}\text { Clinical/ } \\
\text { audiometric } \\
\text { presentation }\end{array}$ & Preliminary MRI findings & $\begin{array}{l}\text { Interval between } \\
\text { MRI and HRCT }\end{array}$ & Subsequent HRCT findings & $\begin{array}{l}\text { Correlation between MRI and } \\
\mathrm{HRCT} \text { findings }\end{array}$ \\
\hline $1 / F / 43$ & $\begin{array}{l}\text { Asymmetric (R) } \\
\text { SNHL }\end{array}$ & $\begin{array}{l}\text { Intermediate T1 signal and } \\
\text { PCE in (B/L) FA regions + } \\
\text { pericochlear regions }\end{array}$ & 1 month & $\begin{array}{l}\text { B/L fenestral and pericochlear } \\
\text { hypodense plaques }\end{array}$ & $\begin{array}{l}\text { MRI findings closely match } \\
\text { HRCT }\end{array}$ \\
\hline 2/M/28 & $\begin{array}{l}\text { Asymmetric (L) } \\
\text { SNHL }\end{array}$ & Reported normal & 4 months & $\begin{array}{l}\text { B/L fenestral hypodense } \\
\text { plaques. No pericochlear } \\
\text { disease }\end{array}$ & $\begin{array}{l}\text { Otosclerosis missed on MRI } \\
\text { at first read. Retrospective } \\
\text { evaluation showed very } \\
\text { subtle focal PCE in (B/L) FA }\end{array}$ \\
\hline 3/F/57 & $\begin{array}{l}\text { Asymmetric (L) } \\
\text { SNHL }\end{array}$ & $\begin{array}{l}\text { Intermediate T1 signal and } \\
\text { PCE in (B/L) FA + } \\
\text { pericochlear regions. Also } \\
\text { enhancement around } \\
\text { (B/L) SCC }\end{array}$ & 2 weeks & $\begin{array}{l}\text { B/L fenestral and pericochlear } \\
\text { hypodense plaques. Also } \\
\text { extensive plaques around } \\
\text { B/L SCC }\end{array}$ & $\begin{array}{l}\text { MRI findings closely match } \\
\text { HRCT }\end{array}$ \\
\hline 4/M/41 & $\begin{array}{l}\text { Asymmetric }(\mathrm{L}) \\
\text { SNHL }\end{array}$ & $\begin{array}{l}\text { Intermediate T1 signal } \\
\text { and PCE at bilateral FA + } \\
\text { (R) pericochlear region }\end{array}$ & 1 month & $\begin{array}{l}\text { B/L fenestral and pericochlear } \\
\text { hypodense plaques. } \\
\text { (R) OW occluded, (L) OW } \\
\text { narrowed }\end{array}$ & $\begin{array}{l}\text { (L) pericochlear disease not } \\
\text { detected on MRI }\end{array}$ \\
\hline $5 / M / 47$ & $\begin{array}{l}\text { (B/L) heavy } \\
\text { SNHL }\end{array}$ & $\begin{array}{l}\text { Intermediate } T 1 \text { signal and } \\
\text { PCE in (B/L) FA + } \\
\text { pericochlear regions }\end{array}$ & 18 months & $\begin{array}{l}\text { B/L fenestral and pericochlear } \\
\text { hypodense plaques }\end{array}$ & $\begin{array}{l}\text { MRI findings closely match } \\
\text { HRCT }\end{array}$ \\
\hline 6/M/61 & $\begin{array}{l}\text { Asymmetric }(\mathrm{L}) \\
\text { SNHL }\end{array}$ & $\begin{array}{l}\text { Intermediate } T 1 \text { signal and } \\
\text { PCE in (B/L) FA + } \\
\text { pericochlear regions. } \\
\text { Also T2 hyperintensity in } \\
\text { (B/L) pericochlear regions }\end{array}$ & 2 months & $\begin{array}{l}\text { B/L fenestral and pericochlear } \\
\text { hypodense plaques. } \\
\text { (L) RW obliterated }\end{array}$ & $\begin{array}{l}\text { MRI findings closely match } \\
\text { HRCT }\end{array}$ \\
\hline 7/M/64 & $\begin{array}{l}\text { (B/L) heavy } \\
\text { SNHL }\end{array}$ & $\begin{array}{l}\text { Intermediate T1 signal and } \\
\text { PCE in (B/L) FA + } \\
\text { pericochlear regions. Also } \\
\text { T2 hyperintensity in (B/L) } \\
\text { pericochlear regions. Right } \\
\text { IAC diverticulum }\end{array}$ & 1 week & $\begin{array}{l}\text { B/L fenestral and pericochlear } \\
\text { hypodense plaques } \\
\text { Right IAC diverticulum }\end{array}$ & $\begin{array}{l}\text { MRI findings closely match } \\
\text { HRCT }\end{array}$ \\
\hline 8/M/46 & (R) $\mathrm{MHL}$ & $\begin{array}{l}\text { Intermediate } T 1 \text { signal and } \\
\text { PCE in (B/L) FA + } \\
\text { pericochlear regions }\end{array}$ & 1 month & $\begin{array}{l}\text { B/L fenestral and pericochlear } \\
\text { hypodense plaques. } \\
\text { (R) OW obliterated }\end{array}$ & $\begin{array}{l}\text { MRI findings closely match } \\
\text { HRCT }\end{array}$ \\
\hline 9/F/61 & $\begin{array}{l}\text { (B/L) heavy } \\
\text { SNHL }\end{array}$ & $\begin{array}{l}\text { Intermediate } T 1 \text { signal and } \\
P C E \text { in }(B / L) F A+ \\
\text { pericochlear regions. } \\
\text { Possible tiny (R) IAC } \\
\text { diverticulum }\end{array}$ & 1 month & $\begin{array}{l}\text { B/L fenestral and pericochlear } \\
\text { hypodense plaques. } \\
\text { Right IAC diverticulum }\end{array}$ & $\begin{array}{l}\text { MRI findings closely match } \\
\text { HRCT }\end{array}$ \\
\hline
\end{tabular}

$(R)$ right, $(L)$ left, $(U / L)$ unilateral, $(B / L)$ bilateral, $F A$ fissula antefenestram, OW oval window, $R W$ round window, $P C E$ post-contrast enhancement, $I A C$ internal auditory canal 
(who are not clinically suspected with otosclerosis) and/ or PT may undergo MRI of the temporal bones as firstline imaging, instead of HRCT [7-9]. The MRI features of otosclerosis are not as well-known as HRCT features and this may lead to diagnostic difficulties when patients are imaged with MRI as the first line of investigation, especially with no clinical suspicion [1, 2, 7-9]. Literature review showed only a few case reports and small case series published about the role of MRI as the firstline modality in the diagnosis of otosclerosis [7-9]. The aim of our retrospective study was to describe and validate the subtle findings on temporal bone MRI, suggestive for the diagnosis of otosclerosis, by eventual comparison to the gold-standard examination for this disease, i.e. HRCT. To the best of our knowledge, ours is the largest case series of patients diagnosed with otosclerosis (in the absence of clinical suspicion) on primary MRI.

\section{Methods}

This retrospective study was approved by the institutional (University Hospitals, KU Leuven, Belgium) ethics committee and need for informed consent was waived.
Using key search words 'MRI otosclerosis', we found 15 cases in the PACS of the radiology department of our institute (University Hospitals, KU Leuven, Belgium), performed from 2003 to 2018. Of these 15 cases, 2 patients were known cases of otosclerosis, already treated with stapedectomy, and were excluded from the study. The remaining 13 patients had pre- and post-contrast MRI performed as firstline modality for the evaluation of unilateral SNHL to rule out acoustic neuroma (8 patients), heavy bilateral SNHL (3 patients), unilateral MHL (1 patient) and bilateral PT with unilateral MHL (1 patient). There was no clinical suspicion for otosclerosis in any of these 13 cases. All these MR studies were read and reported by the same senior consultant radiologist with more than 30 years of experience in head and neck radiology.

All 13 patients underwent first-line MRI on a 1.5 or 3 $\mathrm{T}$ scanner using a standard head coil, and comparable sequences on both machines. Detailed parameters used on the $3 \mathrm{~T}$ machine were as follows: axial T2W spinecho sequence through the entire brain and posterior fossa (TR/TE 3000/80 ms, slice thickness $4 \mathrm{~mm}$, FOV $230 \mathrm{~mm}$, matrix $400 \times 320 \mathrm{~mm}$, acquired/reconstructed

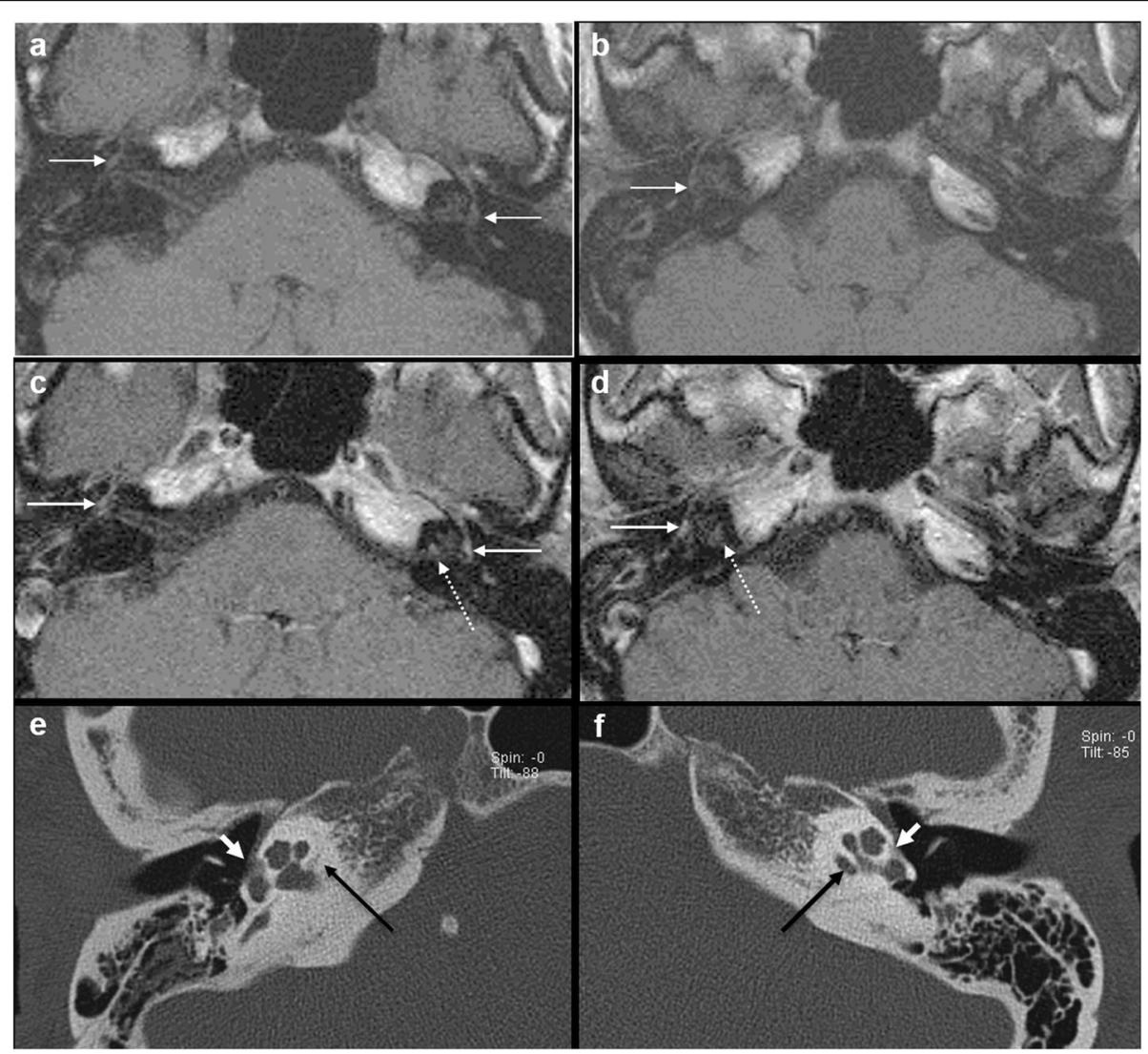

Fig. 1 A 43-year-old female patient with right-sided SNHL (case 1). Axial T1W MR images (a, b) show subtle intermediate T1 signal in bilateral FA regions (arrows). Contrast-enhanced axial T1W images $(\mathbf{c}, \mathbf{d})$ show moderate post-contrast enhancement in bilateral FA regions (arrows) and mild post-contrast enhancement in bilateral pericochlear regions (dashed arrows). Subsequent axial HRCT images (e, $\mathbf{f}$ ) confirm bilateral fenestral otosclerotic plaques (short white arrow) and pericochlear plaques (black long arrows) 
resolution $0.58 \times 0.72 \mathrm{~mm} / 0.45 \times 0.45 \mathrm{~mm})$, CISS sequence through the cerebellopontine angles and internal acoustic meati (IAM) (TR/TE 2000/180 ms, slice thickness $0.7 \mathrm{~mm}$, FOV $160 \mathrm{~mm}$, matrix $400 \times 280$, acquired/ reconstructed resolution $0.4 \times 0.57 \mathrm{~mm} / 0.31 \times 0.31 \mathrm{~mm}$ ) and axial T1W SE sequence through the IAM, repeated after injection of gadolinium in the axial and coronal plane (TR/TE 600/9.4 ms, slice thickness $2.2 \mathrm{~mm}$, FOV $230 \mathrm{~mm}$, matrix $320 \times 240$, acquired/reconstructed resolution $0.72 \times 0.96 \mathrm{~mm} / 0.48 \times 0.48 \mathrm{~mm})$. Subsequent HRCT of the temporal bones was performed on a multidetector CT scanner (depending on the machine, 110$120 \mathrm{kV}, 100-250 \mathrm{mAs}$, slice thickness $0.4-0.5 \mathrm{~mm}$, FOV $80 \mathrm{~mm}$, in plane spatial resolution $0.15 \times 0.15 \mathrm{~mm}$ ), with reformattings in the axial and coronal planes, respectively in the plane of and perpendicular to the lateral semi-circular canals (SCC). All HRCT studies were read by same consultant radiologist.

\section{Results}

Of these 13 cases, 12 cases were reported as showing MR imaging features suspicious for otosclerosis. One
MRI was reported as normal. Subsequent HRCT was performed in 9 out of 13 patients and confirmed the findings of otosclerosis in all 9 cases. The single MR study which was reported as normal subsequently showed otosclerosis on HRCT. The correlation between primary MRI findings and subsequent HRCT findings in these 9 patients is described in Table 1.

Intermediate T1 signal in bilateral fissulae antefenestram (FA) followed by mild-moderate post-contrast enhancement in these locations was seen in all 8 cases reported suspicious for otosclerosis on MRI (Fig. 1). The single MRI which was reported as normal initially (case no. 2) also showed these findings on retrospective evaluation, although they were very subtle (Fig. 2). In addition to these findings, intermediate $\mathrm{T} 1$ signal and mildmoderate post-contrast enhancement in bilateral pericochlear regions were seen in 7 out of the 8 positive cases (Figs. 3 and 4). Of these 7 cases, 1 case also showed enhancement on MR around bilateral SCC (case 3) (Fig. 4). All these 7 cases were reported as 'suspicious for bilateral fenestral and cochlear otosclerosis on MRI, further confirmation with HRCT suggested'. One case showed

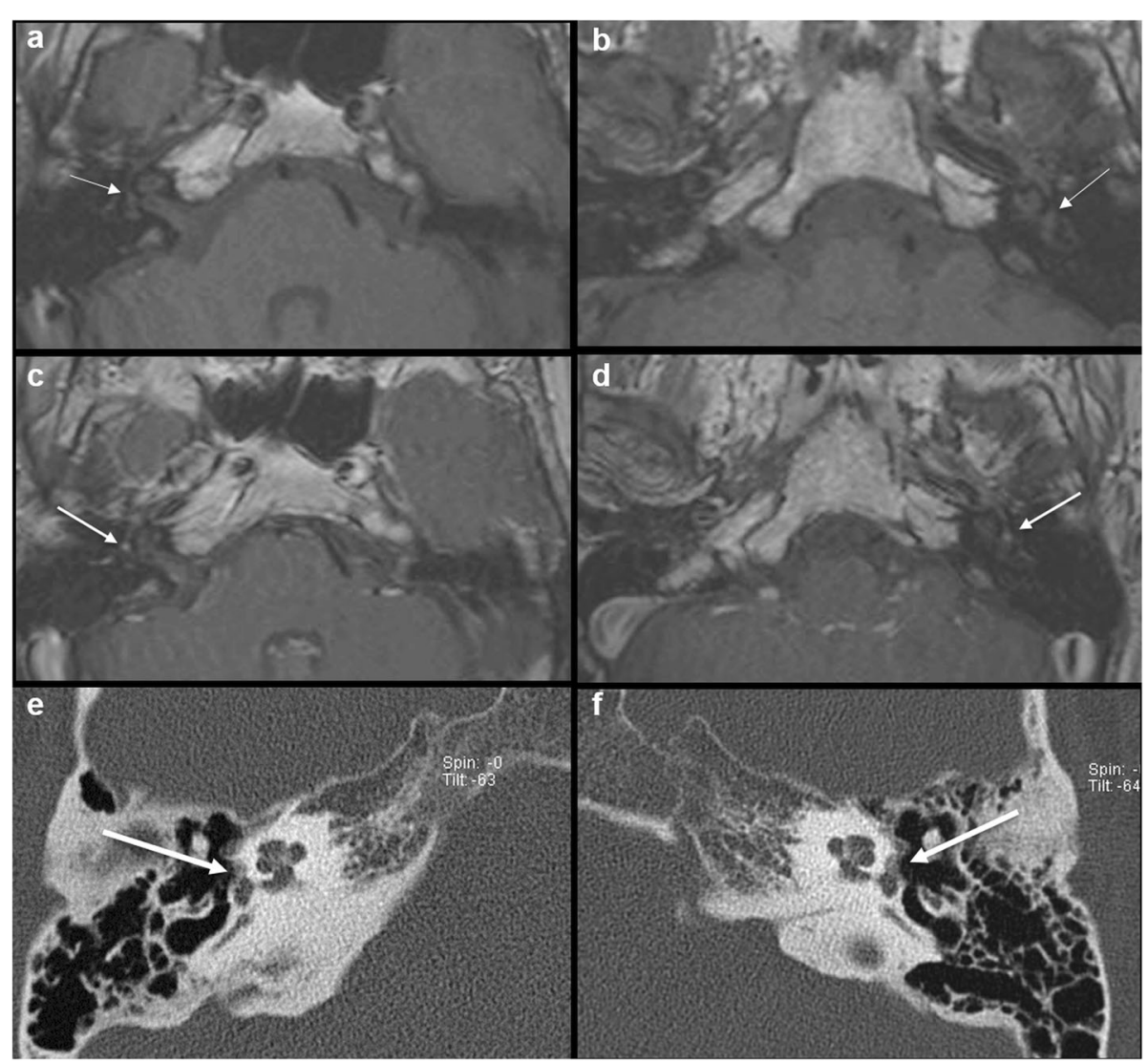

Fig. 2 A 28-year-old male patient with left-sided SNHL (case 2). This was the case where otosclerosis was missed on first read MRI. Retrospective evaluation of axial T1W MR images $(\mathbf{a}, \mathbf{b})$ shows very subtle intermediate T1 signal in bilateral FA regions (arrows). Contrast-enhanced axial T1W images ( $\mathbf{c}, \mathbf{d})$ show subtle focal post-contrast enhancement in bilateral FA regions (arrows). Axial HRCT images (e, $\mathbf{f}$ ) show bilateral fenestral otosclerotic plaques (arrows). There was no pericochlear disease seen on HRCT 


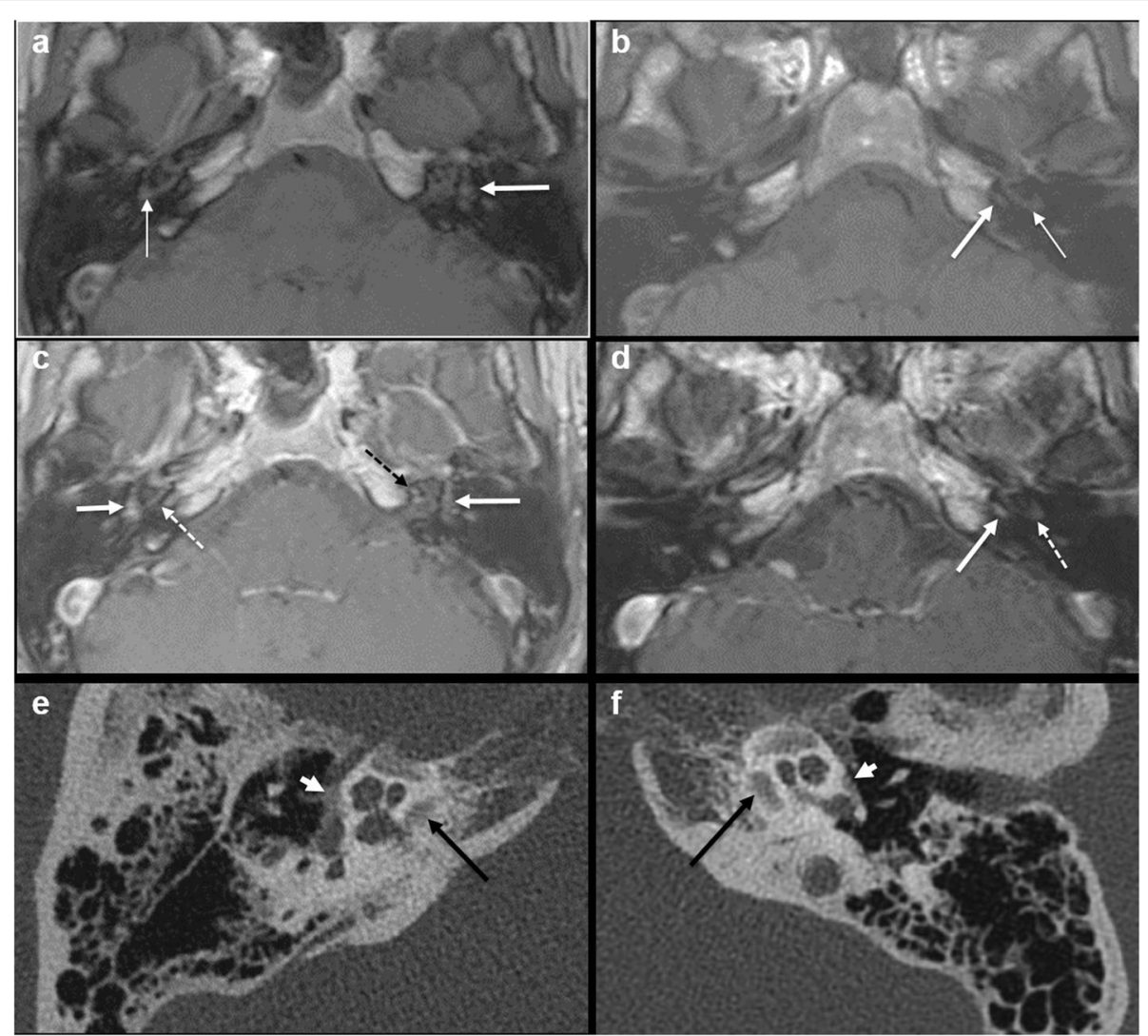

Fig. 3 A 46-year-old male patient with right-sided MHL (case 8). Axial T1W MR image (a) shows intermediate T1 signal around the basal turn of the right cochlea (thin arrow) and in the left FA region (thick arrow). Axial T1W MR image at a lower level (b) shows intermediate T1 signal around the basal turn of the left cochlea (thin arrow) and another separate focus of intermediate signal in the left pericochlear region (thick arrow). Contrast-enhanced axial T1W image (c) shows moderate post-contrast enhancement in bilateral FA regions (arrows) and mild enhancement around the basal turns of cochleae (dashed arrows). Contrast-enhanced axial T1W image at a lower level (d) shows mild enhancement around the basal turn of left cochlea (dashed arrow) and another focus of enhancement in the left pericochlear region (arrow). Subsequent axial HRCT images (e, f) confirm bilateral fenestral otosclerotic plaques (short white arrows) and pericochlear plaques (black long arrows)

pericochlear enhancement only on the right (case no. 4); this was reported as 'suspicious for bilateral fenestral otosclerosis, also likely cochlear involvement on the right, further confirmation with HRCT suggested' (Fig. 5). The single MRI which was reported as normal initially did not show pericochlear enhancement on either side on retrospective evaluation.

Subsequent HRCT showed bilateral fenestral and pericochlear hypodense plaques i.e. fenestral and cochlear otosclerosis in all 8 cases which were diagnosed as otosclerosis on MRI. The case which was reported as normal on MRI showed bilateral fenestral otosclerosis on HRCT.

Curvilinear non-enhancing T2 hyperintensities were seen in bilateral pericochlear regions in 2 out of the 7 cases with matching MRI and HRCT findings (case nos. 6 and 7) (Fig. 6); MRI detected IAC diverticula confirmed on HRCT in 2 out of the 7 matched cases (case nos. 7 and 9) (Fig. 6).

\section{Discussion}

The initial lytic, active or 'spongiotic' phase of otosclerosis is characterised by increased cellularity, increased vascularity and decalcification of the otic capsule. The later phase, i.e. the classic 'sclerotic' phase is characterised by decreased cellularity, obliteration of blood vessels and formation of dense lamellar bone in these lesions $[1-4,7-9]$. In fenestral otosclerosis, patients typically experience CHL due to otosclerotic plaques involving and eventually obliterating the margins of the OW and the footplate of the stapes. Cochlear otosclerosis is usually a continuum of fenestral otosclerosis, where foci of demineralised spongy vascular bone are seen in the cochlear capsule, sometimes around the IAC, rarely also around the SCC. Direct injury to the cochlea and spiral ligament due to the lytic/proteolytic enzymes, hyalinisation of the spiral ligament and vascular shuntrelated hypoxia have been implicated as likely causes of 


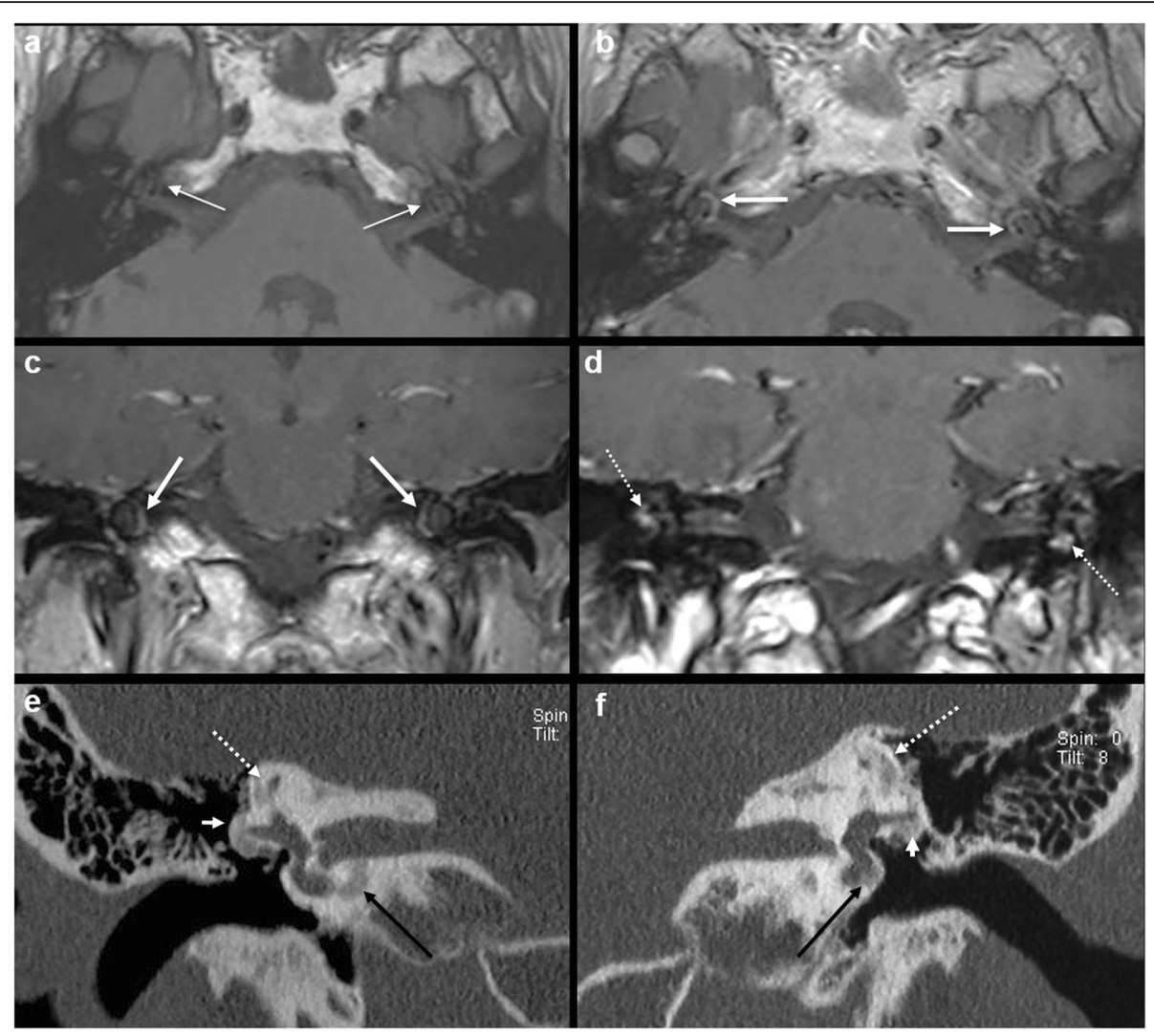

Fig. 4 A 57-year-old female patient with left-sided SNHL (case 3). Axial T1W MR image (a) shows intermediate T1 signal in in bilateral pericochlear regions (arrows). Contrast-enhanced axial T1W MR image (b) and contrast-enhanced coronal T1W MR image (c) show ring-like enhancement in bilateral pericochlear regions (arrows). Contrast-enhanced coronal T1W MR image (d) also shows patchy enhancement surrounding the SCC bilaterally (dashed arrows). Subsequent coronal HRCT images (e, $\mathbf{f}$ ) confirm otosclerotic plaques adjacent to bilateral lateral SCC (short white arrow), superior SCC (dashed arrow) and in bilateral pericochlear regions (long black arrows)

the SNHL occurring in this phase. Vestibular symptoms are known to occur due to vestibular/labyrinthine involvement $[1-4,7,8]$; also, PT may occur due to increased vascularity/arteriovenous microfistulae in the otic capsule $[1,2,10,11]$. Sometimes, patients with fenestral and cochlear otosclerosis may present with MHL due to a combination of CHL at the OW and SNHL at the cochlea $[1-4,8]$.

The clinical diagnosis of fenestral otosclerosis is based on the classic findings of CHL/Carhart's notch (50-60 $\mathrm{dB})$, absent stapedial reflexes, clean middle ear cavity and normal tympanic membrane. These patients typically undergo HRCT of the temporal bones as first-line imaging. HRCT plays an important role in detecting the size and location of otosclerotic plaques, assessing the status of OW and RW and ruling out concurrent middle ear/inner ear pathology [1-6, 8]. HRCT can detect very small hypodense demineralised otosclerotic foci, first occurring at the region of the FA, anterior to the OW. As the disease progresses, hypodense plaques are seen to extensively involve the margins of the OW, RW and eventually, the pericochlear regions. The classic HRCT imaging features of cochlear otosclerosis are distinctive bilateral pericochlear hypodense rings (described in old literature as the '4th ring of Valvassori') [1-6]. Small IAC diverticula (focal hypodense outpouchings at the anterolateral IAC) are also described as HRCT features of advanced/cavitatory otosclerosis [12, 13]. Hypodense haloes may also be seen around the SCC in advanced disease $[1,2]$.

Occasionally, patients with otosclerosis who present with unilateral/asymmetric SNHL and /or vestibular symptoms are clinically suspected with retrocochlear pathologies such as acoustic neuroma. Also, unilateral/ bilateral PT may be clinically confounding [1, 2, 7-11]. These patients may undergo a primary MRI of the temporal bones instead of HRCT [7-9, 14]. The MRI features of otosclerosis are often very subtle and radiologists may be unfamiliar with them [7-9, 14-19]; this may lead to potential misdiagnosis, especially in the absence of clinical suspicion [7-9].

Literature review (Medline search from 1990 to 2019) shows 3 case reports/case series describing the role of MRI as the primary modality in diagnosing clinically 


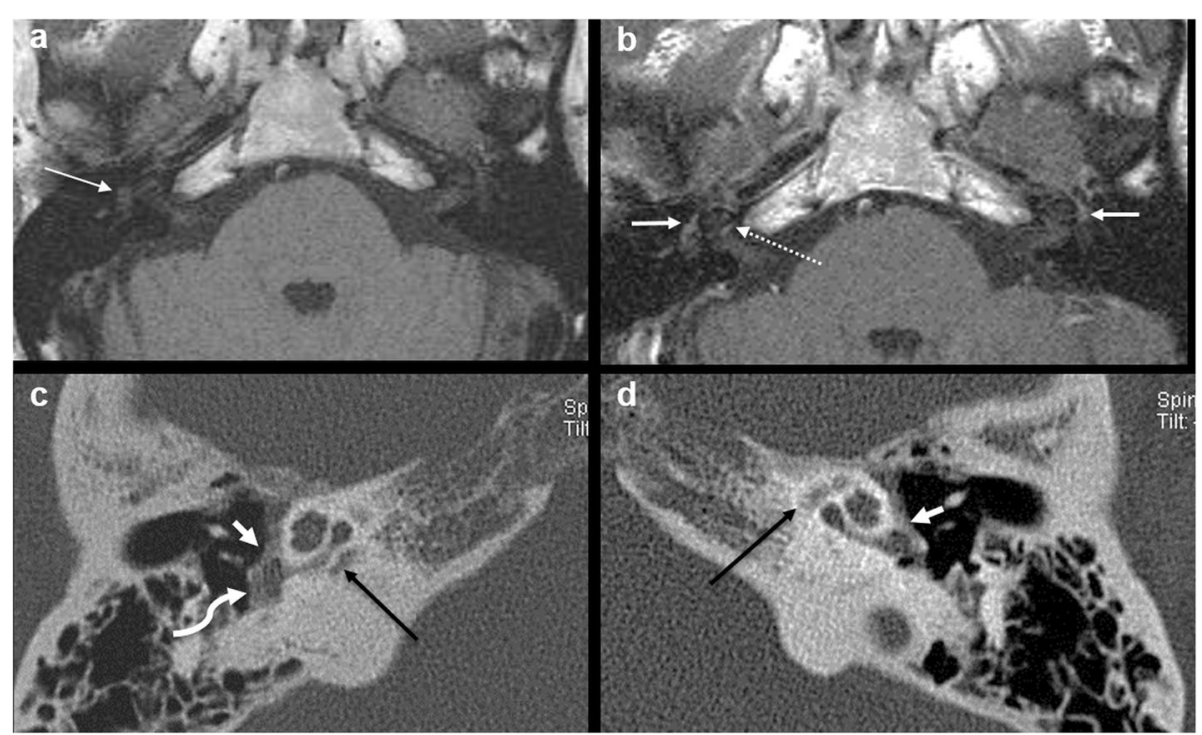

Fig. 5 A 41-year-old male patient with left-sided SNHL (case 4). Axial T1W MR image (a) shows intermediate T1 signal in the right FA (arrow). Contrast-enhanced T1W MR image (b) shows moderate enhancement in bilateral FA regions (arrows) and mild enhancement in the right pericochlear region (dashed arrow). Pericochlear enhancement was not seen on the left. Subsequent axial HRCT images (c, $\mathbf{d}$ ) confirm bilateral fenestral otosclerotic plaques (short white arrows) and pericochlear plaques (black long arrows). The right RW is occluded (curved arrow)

unsuspected otosclerosis [7-9]. Youssef et al. [7] describe a single case of a 48-year-old lady with clinical findings of bilateral SNHL, vertigo and unilateral tinnitus who underwent temporal bone MRI to rule out a retrocochlear pathology. MRI showed soft tissue signal and post-contrast enhancement in bilateral perilabyrinthine and pericochlear regions; it was reported as suspicious for otosclerosis and confirmed on subsequent HRCT. Goh et al., in their case series [8], have described 4 adult cases $(39,50,45$ and 55 years old) with bilateral MHL, unilateral SNHL, unilateral tinnitus and bilateral MHL, and bilateral SNHL respectively. All 4 cases underwent temporal bone MRI as firstline imaging. None of the cases were clinically suspected with otosclerosis. The positive findings in these cases leading to suggestion of otosclerosis were intermediate $\mathrm{T} 1$ signal in the perilabyrinthine and pericochlear regions,

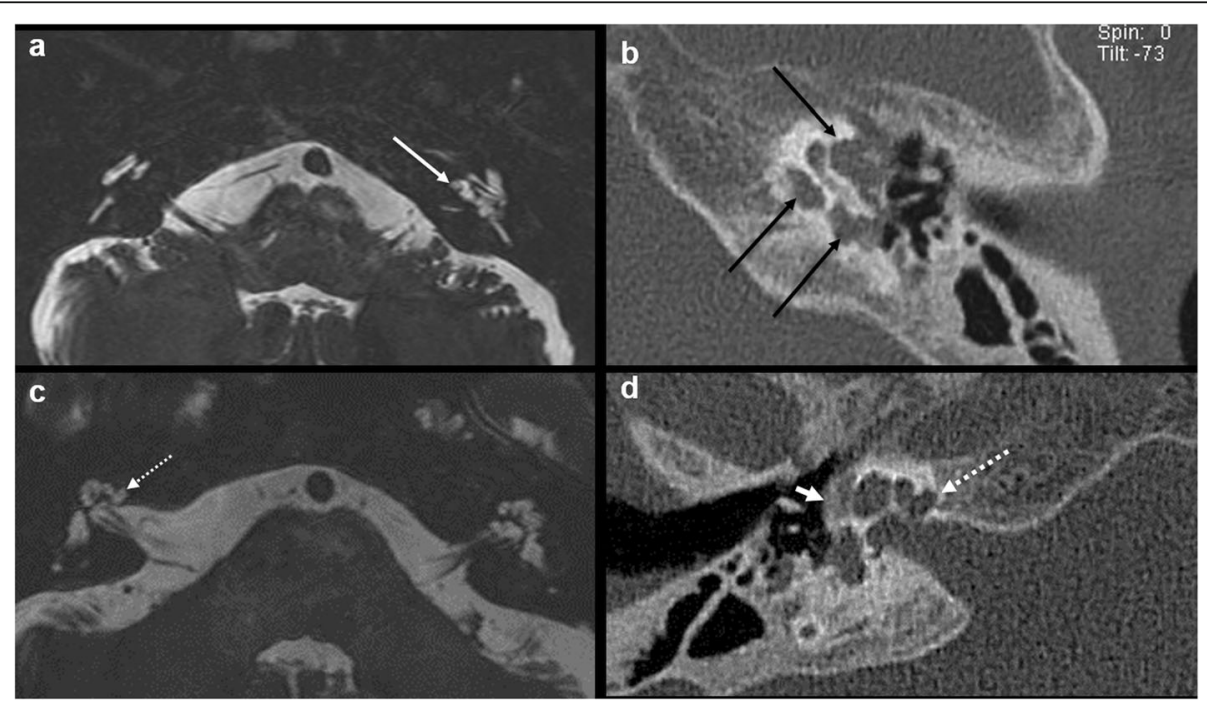

Fig. 6 A 64-year-old male patient with heavy bilateral SNHL (case 7). Axial CISS image (a) shows curvilinear T2 hyperintensities (arrow) surrounding the left cochlea. Subsequent axial HRCT image (b) confirms extensive very hypodense plaques (arrows) in the left pericochlear region, likely long-standing disease. Axial CISS image (c) at a lower level also shows a small right IAC diverticulum (dashed arrow), confirmed on subsequent axial HRCT image (d) as an 'ear-like' outpouching anterior to the right IAC (dashed arrow). Also note the large plaque in the right FA region (short arrow) 
mild-moderate enhancement in these regions on postcontrast images and in two cases, pericochlear T2 hyperintense signal. Subsequent HRCT confirmed fenestral and cochlear otosclerosis in all 4 cases. Stimmer et al. described a single case of a 29-year-old lady who underwent primary temporal bone MRI to evaluate her bilateral MHL. MRI showed increased T1 and T2 signal with strong post-contrast enhancement in the perilabyrinthine regions. HRCT confirmed bilateral fenestral and cochlear otosclerosis.

A few other authors have also described similar MRI features of otosclerosis [14-19]. However, in all these studies, otosclerosis was either already known over years [17] or primarily diagnosed with a positive initial HRCT and MRI was performed as second-line imaging [14-16, 18, 19].

To the best of our knowledge, our study describes the largest number of patients from a single institute (8 cases) correctly diagnosed with otosclerosis, in the absence of clinical suspicion, on primary MRI, prior to HRCT. In our experience too, the imaging findings of intermediate $\mathrm{T} 1$ signal and mild-moderate post-contrast enhancement in the perilabyrinthine and pericochlear regions were most crucial for suspecting otosclerosis (see Table 1). We detected extensive enhancement around bilateral SCC in 1 of our positive cases. As described by Goh et al. and Ziyeh et al., we also detected pericochlear curvilinear non-enhancing T2 hyperintensities in 2 of our positive cases; these regions appeared as very dark/very low-attenuation haloes on subsequent HRCT, presumably indicating chronic disease $[8,15]$. Interestingly, we also detected tiny unilateral IAC diverticula in 2 of the positive cases on MRI, confirmed on subsequent HRCT.

In summary, in 7 out of our 9 cases, MRI findings of bilateral fenestral and cochlear otosclerosis matched perfectly with those of subsequent HRCT. Of the remaining 2 cases, MRI correctly detected bilateral fenestral otosclerosis and unilateral cochlear involvement in 1 case; otosclerosis was missed entirely on MRI in 1 case. This case series shows a very good 'positive catch of otosclerosis', in the first 'diagnostic net' itself i.e. MRI, even in the absence of clinical suspicion. This correct diagnosis prompted the clinician to obtain the appropriate confirmatory diagnostic test, i.e. HRCT, thus leading to adequate clinical management. Our hypothesis is that in the appropriate clinical setting (young or middle-aged patients with SNHL, MHL and/or tinnitus), familiarity with MRI features of otosclerosis and a high index of suspicion would aid the reporting radiologist in arriving at the correct diagnosis.

Some of the limitations of our study include the relatively small data set from a single institute and the fact that all the MRI scans as well as the subsequent HRCT studies were read by the same senior experienced head- neck radiologist. Moving forward, it would be interesting to have more studies performed and published on this subject, with larger number of cases and comparison between various readers for assessing pick-up rate/variability in pick-up of subtle MRI findings of otosclerosis.

The MRI features of cochlear otosclerosis may be mimicked by other diseases that demineralise the otic capsule, typically osteogenesis imperfecta and Paget's disease. These conditions also show soft tissue signal on $\mathrm{T} 1$ and post-contrast enhancement in the otic capsule. The HRCT findings may also be very similar, especially in otosclerosis and osteogenesis imperfecta. However, the entirely different spectrum of clinical manifestations and involvement of other bones are sufficient to differentiate between these pathologies [1-3, 8, 20-22].

Fenestral otosclerosis is treated by stapedotomy and a stapes prosthesis insertion. Cochlear otosclerosis on the other hand may be medically treated with fluorides. Patients with profound bilateral SNHL due to otosclerois may derive benefit from cochlear implantation $[1-4,8]$.

\section{Conclusion}

The MRI findings of otosclerosis are subtle and may be overlooked. Keeping in mind the clinical context and being conversant with these imaging features is likely to increase the pick-up of these cases on MRI. By recommending the correct subsequent investigation i.e. HRCT, further diagnostic delay can be avoided and the correct treatment installed.

\section{Abbreviations}

CEMRI: Contrast-enhanced MRI; CHL: Conductive hearing loss; FA: Fissula antefenestram; HRCT: High-resolution CT; IAC: Internal auditory canal; IAM: Internal acoustic meatus; MHL: Mixed hearing loss; OW: Oval window; PT: Pulsatile tinnitus; RW: Round window; SCC: Superior semi-circular canal; SE: Spin echo; SNHL: Sensorineural hearing loss

\section{Authors' contributions \\ Bela Purohit is responsible for study concept, analysis of data, manuscript preparation, literature search and image formatting. Katya Op de beeck is responsible for literature search. Robert Hermans is the guarantor of integrity of the study and is responsible for study concept, collection of data and manuscript editions. The author(s) read and approved the final manuscript.}

\section{Funding}

This work was not sponsored by grants or any funding organisation or company.

Availability of data and materials

Approved from institutional committee

Ethics approval and consent to participate

Approved by institutional ethics committee

Consent for publication

Not applicable

Competing interests

The authors declare that they have no competing interests. 
Received: 27 January 2020 Accepted: 23 April 2020

Published online: 19 May 2020

References

1. Schwartz JD, Mukherji SK (2009) The inner ear and otodystrophies. In: Swartz JD, Loevner LA (eds) Imaging of the Temporal Bone, 4th edn. Thieme, New York, pp 298-411

2. Purohit B, Hermans $R$, Op de beeck K (2014) Imaging in otosclerosis: a pictorial review. Insights Imaging 5:245-252

3. Andreu-Arasa VC, Sung EK, Fujita A, Saito N, Sakai O (2019) Otosclerosis and dysplasias of the temporal bone. Neuroim Clin N Am 29:29-47

4. Cureoglu S, Baylan MY, Paparella MM (2010) Cochlear otosclerosis. Curr Opin Otolaryngol Head Neck Surg 18:357-362

5. Lee TC, Aviv RI, Chen JM, Nedzelski JM, Fox AJ, Symons SP (2009) CT grading of otosclerosis. AJNR Am J Neuroradiol 30:1435-1439

6. Naumann IC, Porcellini B, Fisch U (2005) Otosclerosis: incidence of positive findings on high resolution computed tomography and their correlation to audiological test data. Ann Otol Rhinol Laryngol 114:709-716

7. Youssef O, Chandrasekhar S, Rosen A, Lee HJ (1998) Cochlear otosclerosis; the current understanding. Ann Otol Rhinol Laryngol 107:1076-1079

8. Goh JPN, Chan LL, Tan TY (2002) MRI of cochlear otosclerosis. Br J Radiol 75: 502-505

9. Stimmer H, Arnold W, Schwaiger M, Laubenbacher C (2002) Magnetic resonance imaging and high-resolution computed tomography in the otospongiotic phase of otosclerosis. ORL J Otorhinolaryngol Relat Spec 64 45-453

10. Pegge SAH, Steens SCA, Kunst HPM, Meijer FJA (2017) Pulsatile tinnitus: differential diagnosis and radiological work-up. Curr Radiol Rep 5:5

11. Hofmann E, Behr R, Neumann-Haefelin T, Schwager K (2013) Pulsatitle tinnitus: imaging and differential diagnosis. Dtsch Arztebl Int. 110:451-458

12. Pippin KJ, Muelleman TJ, Hill J, Leever J, Staecker H, Ledbetter LN (2017) Prevalence of internal auditory canal diverticulum and its association with hearing loss and otosclerosis. AJNR Am J Neuroradiol 38:2167-2171

13. Wang F, Yoshida T, Shimono M et al (2018) Significance of internal auditory canal diverticula in ears with otosclerosis. Acta Otolaryngol 138:1066-1069

14. Mark AS, Seltzer S, Harnsberger HR (1993) Sensorineural hearing loss: more than meets the eye? AJNR Am J Neuroradiol 14:37-45

15. Ziyeh S, Berlin A, Ross UH, Reinhardt MJ, Schumacher M (1997) MRI of active otosclerosis. Neuroradiology 39:453-457

16. Vicente AO, Chandrasekhar SS, Yamashita HK, Cruz OLM, Barros FA, Penido NO (2015) Magnetic resonance imaging in the evaluation of clinical treatment of otospongiosis: a pilot study. Otolaryngol Head Neck Surg 152: 1119-1126

17. Saunders JE, Derebery MJ, Lo WWM (1995) Magnetic resonance imaging of cochlear otosclerosis. Ann Otol Rhinol Laryngol 104:826-829

18. Sakai O, Curtin HD, Fujita A, Kakoi H, Kitamura K (2000) Otosclerosis: computed tomography and mangetic resonance findings. Am J Otolaryngol 21:116-118

19. Nowe V, Verstreken M, Wuyts FL, Van de Heyning P, De Schepper AM, Parizel PM (2004) Enhancement of the otic capsule in active retrofenestral otosclerosis. Otol Neurotol 25:633-634

20. Ziyeh S, Berger R, Reisner K (2000) MRI-visible pericochler lesions in osteogenesis imperfecta type 1. Eur Radiol 10:1675-1677

21. Alkhadi H, Rissmann D, Kollias SS (2004) Osteogenesis imperfecta of the temporal bone: CT and MR imaging in Van der Hoeve-de Kleyn syndrome. AJNR Am J Neuroradiol 25:1106-1109

22. Ginsberg LE, Elster AD, Moody DM (1992) MRI of Paget disease with temporal bone involvement presenting with sensorineural hearing loss. J Comput Assist Tomogr 16:314-316

\section{Publisher's Note}

Springer Nature remains neutral with regard to jurisdictional claims in published maps and institutional affiliations.

\section{Submit your manuscript to a SpringerOpen ${ }^{\odot}$ journal and benefit from:}

- Convenient online submission

- Rigorous peer review

- Open access: articles freely available online

- High visibility within the field

- Retaining the copyright to your article

Submit your next manuscript at $\boldsymbol{\nabla}$ springeropen.com 